A ncRNA524

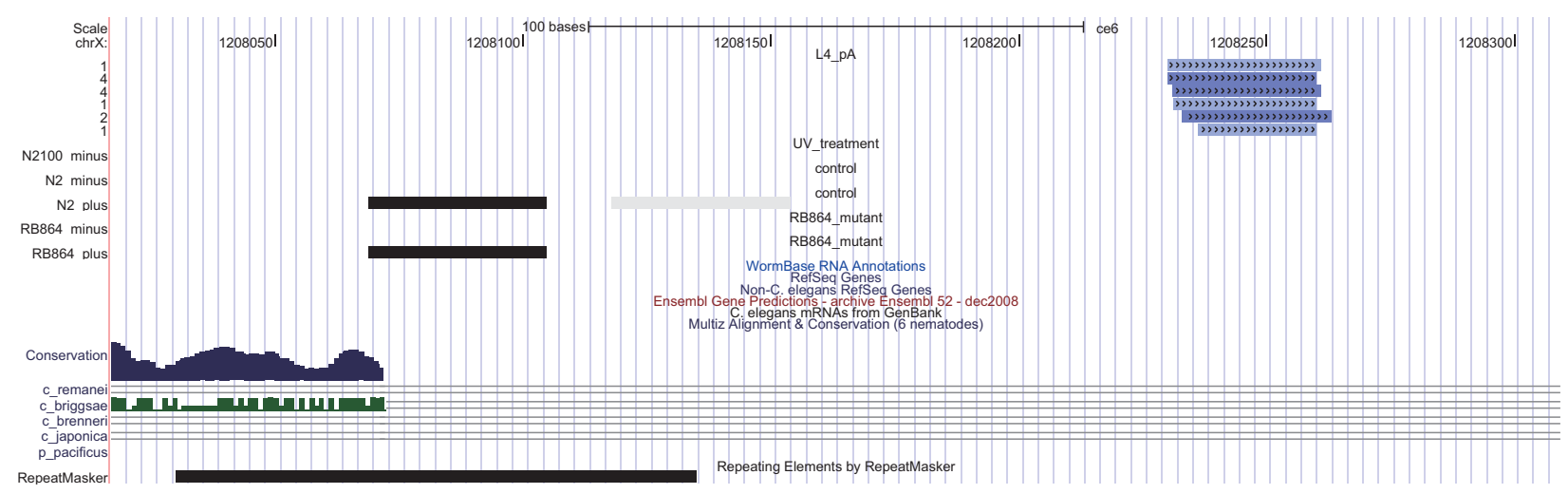

B ncRNA456

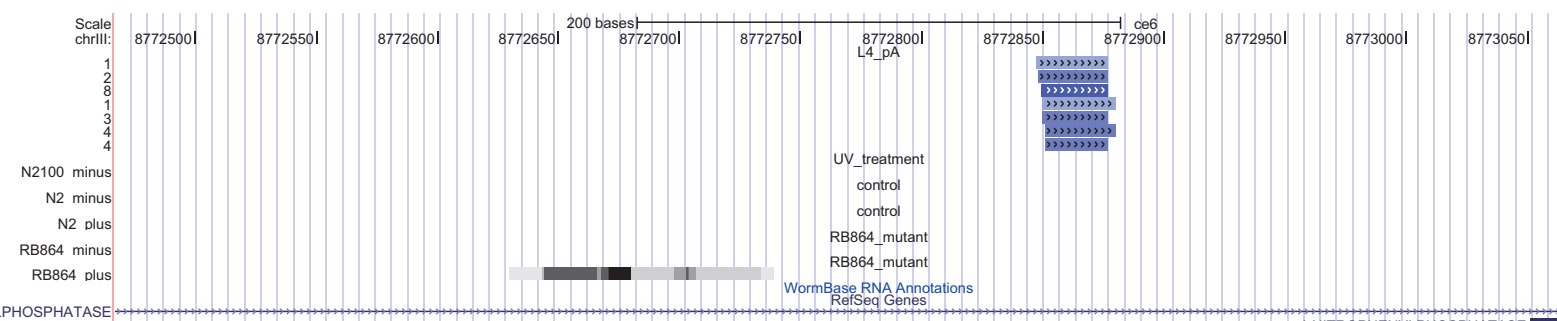

IEYLPHOSPATASE

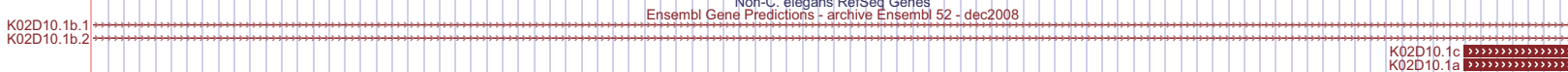
Conservation

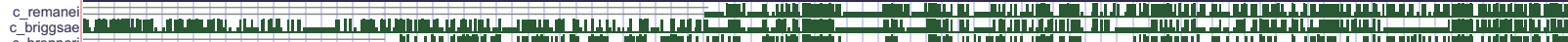

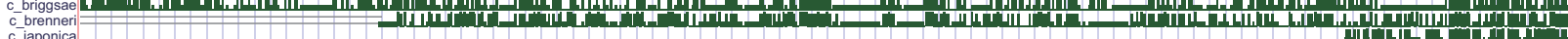
cjaponica RepeatMasker

\title{
C ncRNA415
}

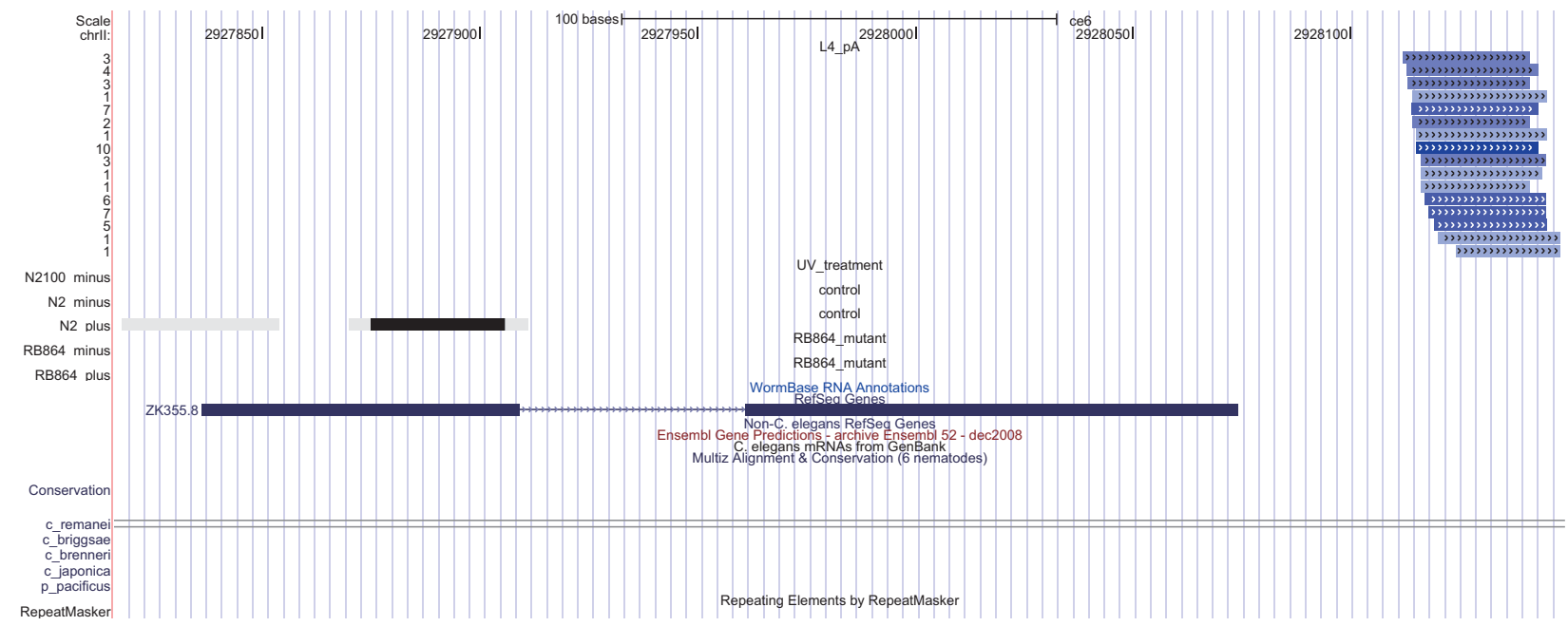


D ncRNA377
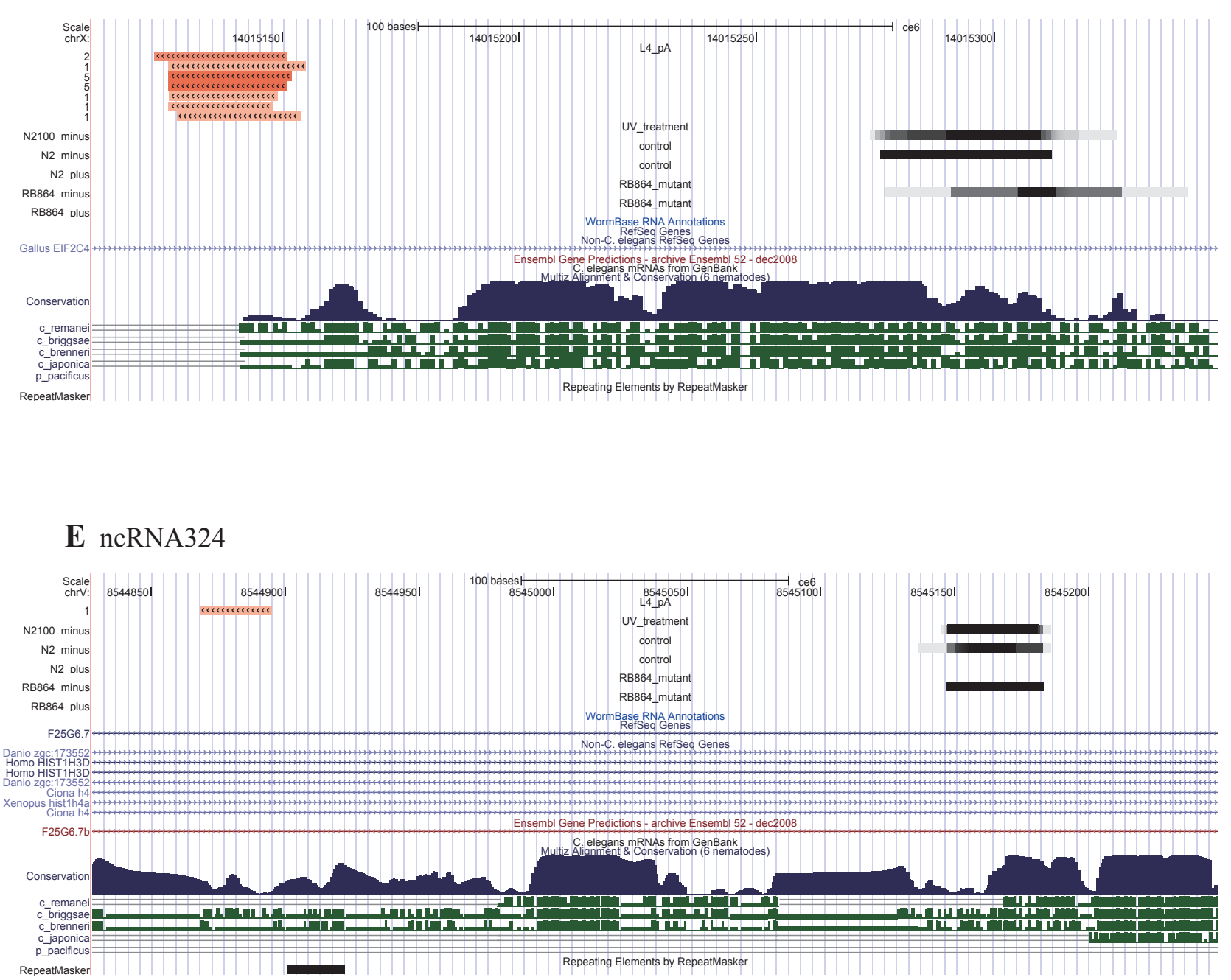